\title{
Editorial
}

\section{Science is human}

\author{
Carlos Renato Zacharias \\ International Journal of High Dilution Research - Editor-in-Chief
}

Collective construction of scientific knowledge is doubtless a major accomplishment of humankind. Sharing of information is a manner of inviting the interested community to participate at each step of such construction. Thus, publication of scientific articles must be regarded as an essential activity or means, because it communicates the results of the work of one or more researchers, in turn based on previous shared knowledge. In this regard, scientific journals play an important role as one of the means of communication. However, they are not merely passive vehicles, but one of the steps of the construction of knowledge itself.

When authors finish their work by submitting an article to a scientific journal, a new stage in the construction of shared scientific knowledge is triggered around two main axes: format and content. The format of scientific articles is much more than mere layout and normalization, but it serves the very specific goal of organizing information to make it easily accessible to the readership. In this regard, publication in the so-called "hard sciences" developed a standard pattern that serves very well this purpose, namely the classic division into "Introduction", "Materials and methods", "Results", "Discussion" and "Conclusions". Due to their nature, the humanities do not adjust well to such model, but nonetheless the corresponding articles must comply with some formal standards including definition of the problem, the approaches to solve it, consistent analysis of the results, and careful citation of references. It is worth to observe that many submissions are rejected by editors for the simple reason that they lack the minimum of organization expected from scientific articles.

Whereas adjustment of format deals with the formal side of articles, analysis of content is a much more "invasive" step, because it is intended to judge on the quality of the information they convey before it is communicated to the scientific community at large. Most journals appeal to the process of peer-review despite it is widely criticized as biased and unfair. However, peer-review was originally intended not only to improve the quality of scientific communication, but also to play an educational role. The feedback it provides to authors might contribute to a thorough review of their basic assumptions, methods and patterns of analysis that might influence the performance of scientific work itself. And naturally, peer-review also protects the scientific community from an overload of unneeded, inconsequent or inconsistent information.

Shortly, from the editorial perspective articles are appropriate for publication when their structure is consistent, the background of the studies is properly explained and soundly grounded on reliable sources, the methods are clearly described and validated, analysis is coherent, the conclusions are systematically inferred from the data. And they have a pinch of originality!

The reason behind this painstaking process is the constant concern of editors with the possibility of publishing an inappropriate article and rejecting an appropriate one. However, the scientific community has some devices to check the damage. In the former case, a "false positive", the scientific community might simply ignore the offending piece or criticize it publicly in the same or other journals. This will certainly upset authors or funding agencies, however, science will escape unharmed. This mechanism is so consistent, that even biased criticism grounded on motives other that the interest of science might in turn become the target of public rebuttal. Shortly, the current mechanism of scientific publication allows for damage control and along that process, all the involved parties and the scientific community at large become more experienced and mindful of possible flaws. 
In the case of "false negatives", however, the problem is quite different. When an article is not published, the scientific community is shunned from certain subjects, ideas, results, methods or hypotheses. Sometimes the authors stubbornly insist, improve the article, and look for other journals until the article is finally published. In that case, the damage is checked and science emerges once again unharmed. However, the opposite is also true: articles might be as innovative and diverging from the mainstream as for the earnest of peers not to be able to understand it or to judge it on its pure merits. Rejection of appropriate articles grounded on a fear of the unknown and unfamiliar leads to an irreparable loss of opportunity to bring something new into and to open paths for science.

It might been adduced that science is under a permanent process of transformation and thus, sooner or later an unconventional topic will come back to the fore, perhaps within a different context, or because better adjusted criteria will have developed meanwhile to judge it more appropriately. However, the crux of the matter is the fact that when editors do not dare to publish articles describing novel notions, methods or results provided they comply with the formal requirements described above, rather than contributing to the advancement, we are involuntarily blocking the advancement of science by clinging to the present state of the art under the disguise of safety and responsibility.

Nevertheless, one must keep in mind that publication is not the primary goal of research, and that sharing knowledge only makes sense when the scientific community is receptive. Unconventional knowledge must be strictly subjected to the criteria of reproducibility and coherence, because it becomes no longer unconventional when several researchers reproduce it, and when it succeeds to interpret reality, otherwise, it is not only unconventional, but also noxious.

Since science has its own mechanisms to judge and rate its production, the task of editors is somewhat lighter. Editors are not responsible for validating or reproducing studies, but first to present them with a readable and complete format to representatives of the scientific community, who will review them in a decentralized, open, multidisciplinary and unbiased manner. Were some referees not stand to their appointed task, editors will see to ensure the fairness of the reviewing process. Thus, journals and researchers play complementary roles in the advancement of science.

Inconsequent, irresponsible and unstructured freedom of expression and rigid censorship refractory to anything new are both noxious to any community. Although reaching a balance between extremes is a universal goal, we discover how much we missed the point only when we act and assess the consequences of our actions. In this regard, science is no different from any other field of human action.

(c)) EY-NC-ND Licensed to GIRI

How to cite this article: Zacharias, CR. The Science is human [editorial]. Int J High Dilution Res [online]. 2012 [cited YYYY Month dd]; 11(39): 43-44. Available from: http://www.feg.unesp.br/ ojs/index.php/ijhdr/article/view/554/563 